\title{
Volume increases in putamen associated with positive symptom reduction in previously drug-naive schizophrenia after 6 weeks antipsychotic treatment
}

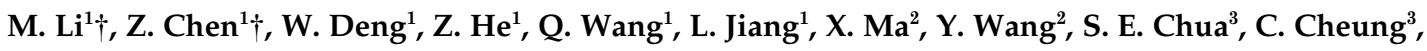 \\ G. M. McAlonan ${ }^{3}$, P. C. Sham ${ }^{3}$, D. A. Collier ${ }^{4}$, Q. Gong ${ }^{5}$ and T. Li ${ }^{1,2 *}$ \\ ${ }^{1}$ The Mental Health Center \& Psychiatric Laboratory, West China Hospital, Sichuan University, Chengdu, Sichuan, China \\ ${ }^{2}$ The State Key Laboratory of Biotherapy, West China Hospital, Sichuan University, Chengdu, Sichuan, China \\ ${ }^{3}$ Department of Psychiatry, The University of Hong Kong, Pokfulam, S.A.R. China \\ ${ }^{4}$ MRC SGDP Centre, Institute of Psychiatry, King's College London, London, UK \\ ${ }^{5}$ Huaxi MR Research Center, Department of Radiology, West China Hospital, Sichuan University, Chengdu, China
}

Background. Brain structure appears to alter after antipsychotic administration, but it is unknown whether these alterations are associated with improvement of psychopathology in patients with schizophrenia. In this study, the authors explore this relationship.

\begin{abstract}
Method. Altogether, 66 first-episode, drug-naive patients with schizophrenia and 23 well-matched healthy controls underwent brain magnetic resonance imaging scans at baseline. All 23 healthy controls and 42 of the patients were rescanned after 6 weeks follow-up. The patients received regular antipsychotic treatment during the 6-week period and their psychopathology was assessed using the Positive and Negative Syndrome Scale (PANSS) at baseline and 6 weeks. The difference in PANSS scores between baseline and 6 weeks was expressed as a ratio of the scores at baseline-'PANSS reduction ratio'. A modified tensor-based morphometry procedure was applied to analyse longitudinal images. Correlations between regional volume changes, PANSS reduction ratio and antipsychotic drug dosages were explored.
\end{abstract}

Results. Compared with healthy controls, there was a significant increase in grey-matter volume of the right putamen in patients after 6 weeks treatment. This volume change was positively correlated with a positive PANSS reduction score but not related to drug dosages.

Conclusions. Putaminal volume increased after 6 weeks antipsychotic treatment in first-episode schizophrenia. The increased volume was closely correlated with improved psychopathology, suggesting the putamen might be a biomarker to predict the treatment response in schizophrenia.

Received 18 March 2011; Revised 30 August 2011; Accepted 13 September 2011; First published online 26 October 2011

Key words: Antipsychotics, longitudinal, MRI scan, putamen, schizophrenia.

\section{Introduction}

Numerous studies have reported brain structural anomalies in patients with schizophrenia, including expansion of lateral ventricles and abnormalities in prefrontal and temporal lobes (Shenton et al. 2001; Honea et al. 2005; Steen et al. 2006). Some anomalous features, such as lower temporal lobe volumes, are even found in first-episode, drug-naive patients with schizophrenia (Jayakumar et al. 2005; Chua et al. 2007; Lui et al. 2009). Thus, regional brain volume

* Address for correspondence: Professor T. Li, Mental Health Center and Psychiatric Laboratory, West China Hospital, Sichuan University, Chengdu, Sichuan 610041, PR China.

(Email: xuntao26@hotmail.com)

$\dagger$ These authors contributed equally to this work. abnormalities appear to be an integral component of the neuropathology of schizophrenia. The impact of antipsychotics on regional brain volume has also received attention. Antipsychotics have been reported to influence the brain structure, especially regional grey-matter volumes, such as basal ganglia, cingulate gyrus and thalamus (Navari \& Dazzan, 2009; Smieskova et al. 2009; Tomelleri et al. 2009) in patients with schizophrenia. Some changes such as an increase in striatal volume might occur even after a very short period of antipsychotic treatment (Chua et al. 2009; Deng et al. 2009). A short-term follow-up period is particularly important in studying the brain structures affected by antipsychotics because, to a certain extent, this excludes the effects of the progression of the disease itself. However, short-term follow-up studies are 
challenging and few in number and the relationship between the brain volume changes and earliest symptomatic improvement of psychosis has not been directly examined.

There is a debate on the time course for antipsychotic treatment response in schizophrenia. The early onset theory indicated that the antipsychotic effect started simultaneously while the drug reached its therapeutic levels (i.e. in the first few days) (Agid et al. 2003; Leucht et al. 2005). The delayed onset theory suggested that a delay exists between the start of antipsychotic treatment and the improvement of psychiatric symptoms. Emsley and his colleagues found that, among 522 first-episode patients with schizophrenia, treatment response was not achieved until 4 weeks in $22.5 \%, 8$ weeks in $11.2 \%$ (Emsley et al. 2006). The current guidelines for the treatment of schizophrenia still recommend clinicians to allow 4-8 weeks for a patient to respond to an antipsychotic drug based on the delayed onset theory (Lehman et al. 2004; Falkai et al. 2005). Moreover, the effects of the treatment are still evaluated by assessing the severity of symptoms mainly with clinical scales such as Positive and Negative Syndrome Scale (PANSS) or Brief Psychiatric Rating Scale and there are no confirmed biomarkers to predict the treatment response objectively.

The purpose of the present study was to quantify brain structural change in first-episode, drug-naive patients with schizophrenia after 6 weeks antipsychotics treatment and to explore the relationship between brain volume change and psychopathology improvement in order to identify potentially biological indicators of treatment efficacy.

\section{Subjects and method}

\section{Subjects}

In total, 66 out-patients and in-patients from the Mental Health Center in West China Hospital were enrolled in the present study from July 2005 to March 2008. All patients were experiencing their first-episode of psychosis and were treatment-naive when recruited to the study. They were assessed by a trained psychiatrist using the Structured Clinical Interview for the DSM-IV (Diagnostic and Statistical Manual of Mental Disorders, fourth edition) and were found to fulfil diagnostic criteria for schizophrenia or schizophreniform psychosis as described in DSM-IV. All patients diagnosed with schizophreniform psychosis were followed up for at least 6 months and found to meet the DSM-IV diagnosis criteria of schizophrenia. Altogether, 23 healthy controls were recruited from the local area by poster advertisement. All controls were screened for the lifetime absence of psychiatric illnesses by using the SCID non-patient version (First et al. 1996). In addition, control subjects were interviewed to ascertain that there was no psychiatric illness in their first-degree relatives. Subjects with evidence of organic brain disorders, alcohol or drug abuse, pregnancy or any severe physical illness, such as brain tumour or epilepsy, were excluded from the study. Six weeks was selected as an initial time point to evaluate the efficiency of the antipsychotics treatment according to previous studies (Harris et al. 2006; Lahti et al. 2009). Before the patients took any antipsychotic medication, they all underwent an assessment of psychopathology and social function by an experienced psychiatrist using PANSS (Kay et al. 1987) and Global Assessment Function (GAF) scale (Morosini et al. 2000), respectively. All patients and controls also underwent magnetic resonance imaging (MRI) brain scans at baseline. At 6 weeks follow-up, MRI scan was scheduled for 42 patients and all controls. Two patients were excluded from later analysis due to unsatisfactory image data in the follow-up MRI scan. All patients with schizophrenia were assessed with the PANSS and GAF scale to record the changes in clinical symptoms and global function after 6 weeks treatment.

In this study, patients with schizophrenia received antipsychotic medication according to the caseclinician's preference. There were 21 , seven, six, two, three and one patients who took risperidone, olanzapine, quetiapine, aripiprazole, sulpiride and haloperidol, respectively (Table 1).

All participants were Han Chinese and righthanded. The handedness of participants was assessed with the Annett's Hand Preference Questionnaire (Annett Handedness Scale) (Annett, 1970). This study was carried out in accordance with the Declaration of Helsinki and was approved by the Institutional Review Board of West China Hospital, Sichuan University. After a complete description of the study to the subjects, written informed consent was obtained.

\section{MRI data acquisition}

The participants were scanned on a Signa 3.0-T scanner (General Electric, Medical Systems, USA) in the Department of Radiology at West China Hospital. A water phantom was scanned to get data quality assurance indexes every time, which was used to evaluate the stability of the MRI machine. High resolution T1 images were acquired by 3D spoiled gradient echo sequence (SPGR) as follows: repetition time $8.5 \mathrm{~ms}$, echo time $3.93 \mathrm{~ms}$, flip angle $12^{\circ}$, slice thickness $1 \mathrm{~mm}$, single shot, field of view $24 \mathrm{~cm} \times 24 \mathrm{~cm}$, matrix 
Table 1. Number of patients and dosage for each type antipsychotic

\begin{tabular}{lllllll}
\hline & Risperidone & Olanzapine & Quetiapine & Aripiprazole & Sulpiride & Haloperidol \\
\hline Number of patients & 21 & 7 & 6 & 2 & 3 & 1 \\
Dosage/day (mg) & 4.42 & 17.36 & 616.66 & 25.46 & 833.33 & 16 \\
& $( \pm 1.18)$ & $( \pm 8.51)$ & $( \pm 222.86)$ & $( \pm 13.43)$ & $( \pm 152.75)$ & - \\
CPZ (mg) equivalent & 220.86 & 347.28 & 822.21 & 339.40 & 416.67 & 800 \\
& $( \pm 58.76)$ & $( \pm 170.11)$ & $( \pm 297.15)$ & $( \pm 179.04)$ & $( \pm 76.38)$ & - \\
\hline
\end{tabular}

$\mathrm{CPZ}$, chlorpromazine.

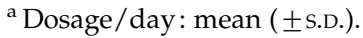

$256 \times 256$ and voxel size $0.47 \times 0.47 \times 1 \mathrm{~mm}^{3}$. This sequence lasted $6 \mathrm{~min}$ and $30 \mathrm{~s}$ and 156 contiguous coronal slices were collected.

\section{Image processing and analysis}

The quality of the brain images was examined and two patients' images were excluded due to the unsatisfactory images in the 6-week follow-up scan. The nonparametric, non-uniformity intensity normalization technique (N3) in MINC software package (http:/ / wiki. bic.mni.mcgill.ca/index.php/MINC) was used to rectify the non-uniformity of a high-magnetic field signal in the remaining images. The baseline images were then processed using voxel-based morphometry in Statistical Parametric Mapping-8 (SPM8; Wellcome Trust Center for Neuroimaging, Institute of Neurology, UK). Customized templates were created from the 63 baseline scans first, then the grey, white and cerebrospinal fluid compartments of the baseline images were obtained by segmenting the original baseline scans using the customized templates, the individual grey-matter images were then normalized to the customized template and issue volume was preserved by modulating voxel value in the grey-matter images. After that, the longitudinal images were processed using tensor-based morphometry (TBM) in SPM8. Each subject's image at follow-up was first registered to the baseline image via a rigid body transformation and then mapped to the baseline image via a high-dimensional deformation. The deformation was then applied to the grey-matter map of the follow-up image and modulated with the Jacobian determinant of this transformation. This yielded a follow-up image in the space of the baseline image, but with intensities reflecting the follow-up image. This image was transformed to standard space using the normalization parameters of the baseline images and modulated to form a product follow-up image. These grey-matter images were smoothed with a 6-mm, fullwidth, half maximum kernel.
A 'difference map' for each individual was calculated from the follow-up smoothed grey-matter image minus the baseline smoothed grey-matter image and reflected the grey-matter volume change between the two time points (Deng et al. 2009).

\section{Statistical analysis}

SPM8 software was used to design the matrix for comparing the difference map of the two groups, with grey-matter volume plus white-matter volume from the baseline scan, sex, age and education years as covariates. A significance criterion was defined using $p<0.05$, with family-wise error rate correction for multiple comparisons. In the patient group, a volume of interest (VOI) was used to extract the eigenvariate values of the region identified as 'changed' during the 6-week period. This VOI was used for further partial correlation analysis with the changes in PANSS scores, the drug dosages and changes in GAF score, controlling the sex, age and education years in SPSS 15.0 statistical software. The difference in PANSS scores and GAF scores between baseline and 6 weeks was expressed as a ratio of the scores at baseline - 'PANSS reduction ratio' and 'GAF increase ratio'.

\section{Results}

\section{Demographic and clinical characteristics}

The demographic characteristics of the subjects are shown in Table 2. Altogether, 14 males and nine females were recruited as healthy controls, with mean age $=22.48$ (s.D. $=5.84$, range $16-39$ ) years and mean duration of education $=12.80$ (s.D. $=3.42$, range $6.5-19$ ) years. The 40 patients who entered the analysis in the present study, including 23 females and 17 males, had mean age $=24.05$ (S.D. $=7.75$, range $16-49$ ) years and mean duration of education $=12.50$ (S.D. $=2.94$, range 4-15) years; the mean duration of disease of the patients was 9.33 (S.D. $=12.72$, range $0.1-60$ ) months and the mean age of onset was 23.30 (s.D. $=7.67$, range 16-40) years when they were recruited. A $\chi^{2}$ test or 
Table 2. Demographic and clinical characteristics for antipsychotic-naive first-episode patients with schizophrenia and healthy comparison subjects

\begin{tabular}{|c|c|c|c|c|c|c|c|}
\hline & \multicolumn{2}{|c|}{$\begin{array}{l}\text { Patients with schizophrenia } \\
(n=40)\end{array}$} & \multicolumn{2}{|c|}{$\begin{array}{l}\text { Healthy controls } \\
(n=23)\end{array}$} & \multirow[b]{2}{*}{$t(2$-tailed $)$} & \multirow[b]{2}{*}{$\mathrm{df}$} & \multirow[b]{2}{*}{$p$} \\
\hline & Mean & S.D. & Mean & S.D. & & & \\
\hline Age (years) & 24.05 & 7.75 & 22.49 & 5.83 & -0.84 & 61 & 0.40 \\
\hline Duration of education (years) & 12.50 & 2.94 & 12.80 & 3.42 & 0.37 & 61 & 0.71 \\
\hline Age of onset (years) & 23.30 & 7.67 & & & & & \\
\hline \multirow[t]{2}{*}{ Duration of disease (months) } & 9.33 & 12.72 & & & & & \\
\hline & $n$ & $\%$ & $n$ & $\%$ & $\chi^{2}$ & $\mathrm{df}$ & $p$ \\
\hline Gender & & & & & 1.97 & 1 & 0.16 \\
\hline Male & 17 & 42.50 & 14 & 60.87 & & & \\
\hline Female & 23 & 57.50 & 9 & 39.13 & & & \\
\hline
\end{tabular}

Table 3. PANSS and GAF reductive ratio after 6 weeks antipsychotic treatment

\begin{tabular}{|c|c|c|c|c|c|c|}
\hline & \multicolumn{2}{|c|}{ Score 0 weeks } & \multicolumn{2}{|c|}{ Score 6 weeks } & \multicolumn{2}{|c|}{ PANSS reduction ratio } \\
\hline & Mean & S.D. & Mean & S.D. & Mean & S.D. \\
\hline \multicolumn{7}{|l|}{ PANSS scores } \\
\hline Total & 103.55 & 15.00 & 68.50 & 17.04 & 0.34 & 0.14 \\
\hline Positive & 26.98 & 5.99 & 14.13 & 4.29 & 0.46 & 0.18 \\
\hline Negative & 18.63 & 6.78 & 15.96 & 6.28 & 0.12 & 0.20 \\
\hline General psychopathology & 49.35 & 8.06 & 34.05 & 9.20 & 0.31 & 0.15 \\
\hline GAF scores & 27.72 & 7.91 & 54.15 & 14.33 & 26.43 & 15.51 \\
\hline
\end{tabular}

PANSS, Positive and Negative Syndrome Scale; GAF, Global Assessment of Functioning.

independent-sample $t$ test was carried out to examine statistical differences in sex, age and education years as appropriate. The dosage of antipsychotic medication taken by each patient was recorded and converted to chlorpromazine equivalent dosages (Table 1) (Atkins et al. 1997; Woods, 2003). After 6 weeks antipsychotic treatment, the PANSS reduction ratio and GAF increase ratio was calculated (Table 3).

\section{Regional grey-matter changes during 6 weeks antipsychotic treatment and correlation with drug dosages and clinical symptom reduction}

Compared with healthy controls, the increased greymatter volume was identified in the right putamen in the patients group following 6 weeks treatment $(x=$ $28, \mathrm{y}=3, \mathrm{z}=4 ; \quad p=0.003 ;$ voxels $=31$; volume $=$ $6.848 \mathrm{~mm}^{3}$ ) (Fig. 1). The volume change in the right putamen was found to be positively correlated with the reduction ratio of positive symptoms, $r=0.350$, $p=0.034$ (Fig. 2). There was no significant correlation with the reduction ratio of negative symptoms, drug dosages or the improvement of global function measured by the GAF.

\section{Discussion}

In this study, we found that an increased volume in putamen was associated with positive symptom reduction in schizophrenia after 6 weeks antipsychotic treatment. There are a number of advantages in this study that help to ensure relatively reliable results. First, medication-naive patients with first-episode schizophrenia were recruited. By analysing these valuable data collected, the influence of confounding factors, such as the neuron response to previous exposure to antipsychotic and chronic disease course, is largely controlled. Second, we used TBM to analyse longitudinal images, which allowed us to perform a relatively unbiased, whole brain analysis. In this analysis, each subject's follow-up image is mapped 

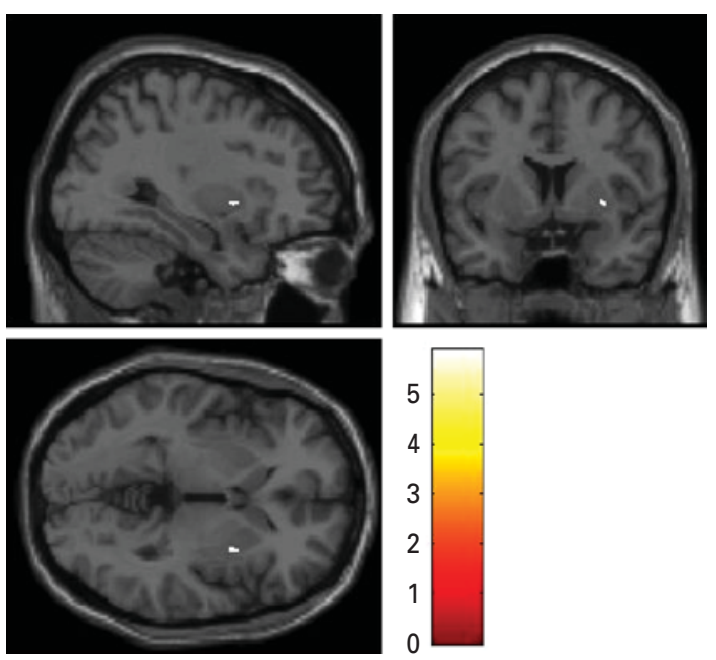

Fig. 1. Difference map between patients and controls. Relative to healthy control subjects, patients with schizophrenia had significantly increased grey-matter volume in the right putamen following 6 weeks antipsychotic treatment $(\mathrm{x}=28, \mathrm{y}=3, \mathrm{z}=4 ; p=0.003$; voxels $=31$; volume $\left.=6.848 \mathrm{~mm}^{3}\right)$.

directly to his or her baseline image via rigid body registration and high-dimensional image warping, which is sensitive to subtle brain volume growth or loss. It is particularly suitable for detecting withinsubject volumetric changes over time (Ashburner \& Friston, 2004; Leow et al. 2006). Finally, we used SPGR sequence to obtain images and N3 correction before TBM processing, and this is considered to be the most stable sequence with least deviation for mapping brain changes when using TBM (Leow et al. 2006).

Using TBM, we found an increased volume of putamen following antipsychotic treatment, in line with previous studies (Dazzan et al. 2005; Taylor et al. 2005). The putamen is located in the rostral part of the striatum and, together with the caudate nucleus, forms the dorsal striatum, a subcortical area rich in dopamine. Dopamine is one of main neurotransmitters in the striatum active in complex cognitive and behavioural symptoms (Volkow et al. 1998; Backman et al. 2000; Reeves et al. 2005; Schultz, 2007). Although the pathophysiological mechanisms underlying schizophrenia are somewhat obscure, the dopamine hypothesis remains one of the most influential (Toda \& Abi-Dargham, 2007; Heinz \& Schlagenhauf, 2010). It is suggested that an excess of dopamine in the subcortical region is associated with positive symptoms, such as hallucinations, delusions, while the negative and cognitive symptoms of schizophrenia are thought to arise from a deficit of dopamine in the cortex (Jentsch \& Roth, 1999; Seeman \& Kapur, 2000; AbiDargham, 2004; Howes \& Kapur, 2009). Consistent with this, we have previously observed a functional deficit in the putamen in a resting-state functional MRI study of treatment-naive, first-episode patients with schizophrenia (Huang et al. 2009). Also, significantly increased activation of the regional cerebral blood flow in putamen has been found after haloperidol treatment (Lahti et al. 2009). Others have reported that patients who were previously medicated had lower metabolic rates and higher volumes than in nevermedicated patients in the putamen (Gur et al. 1998; Shihabuddin et al. 1998; Premkumar et al. 2006). A later study found that putaminal volumes were decreased during the interval if patients discontinued atypical antipsychotics, while increased in patients who continued their antipsychotics including olanzapine, risperidone, or quetiapine (Boonstra et al. 2011). Collectively, these results implicate a functional and structural reaction in the putamen in response to dopaminergic treatment. However, it should note that the putaminal volume deficits might not exist in patients, especially in patients who experienced their first-episode attack or were drug-naive. A few previous studies showed there is no significant volume difference in putamen between first-episode schizophrenia patients and controls (Gur et al. 1998; Lang et al. 2001; Gunduz et al. 2002; Lui et al. 2009).

In the present study, we found that only the right but not the left putaminal volume increased after 6 weeks antipsychotic treatment. This might be related to striatal asymmetry existing in both patients and normal healthy controls. Previous studies have suggested that the basal ganglia, like other brain structures, exhibited hemispheric lateralization. The right striatal volume was larger than the left striatal volume in humans (Ifthikharuddin et al. 2000; Watkins et al. 2001; Yamashita et al. 2011). Left-right asymmetry of striatal dopamine D2 receptors was also detected by Larisch and his colleagues, who showed that D2 binding ratio was higher in the right compared to the left striatum in healthy volunteers (Larisch et al. 1998). In addition, previous studies using a voxel-based morphometry method to study the cerebral asymmetry did not find any differences in grey-matter volume asymmetry (Takao et al. 2010) or basal ganglia asymmetry (Kawasaki et al. 2008) between patients with schizophrenia and healthy controls.

The exact mechanism of enlarged putaminal volume after antipsychotic treatment is unknown. It has been suggested that dopamine plays a role not only as a neurotransmitter but also as a regulator of endogenous neurogenesis in the adult mammalian brain (Borta \& Hoglinger, 2007). Dopaminegic stimulation in vitro inhibits neural stem cell (NSC) proliferation and haloperidol, as well as risperidone, dopamine receptor antagonists, may increase adult 


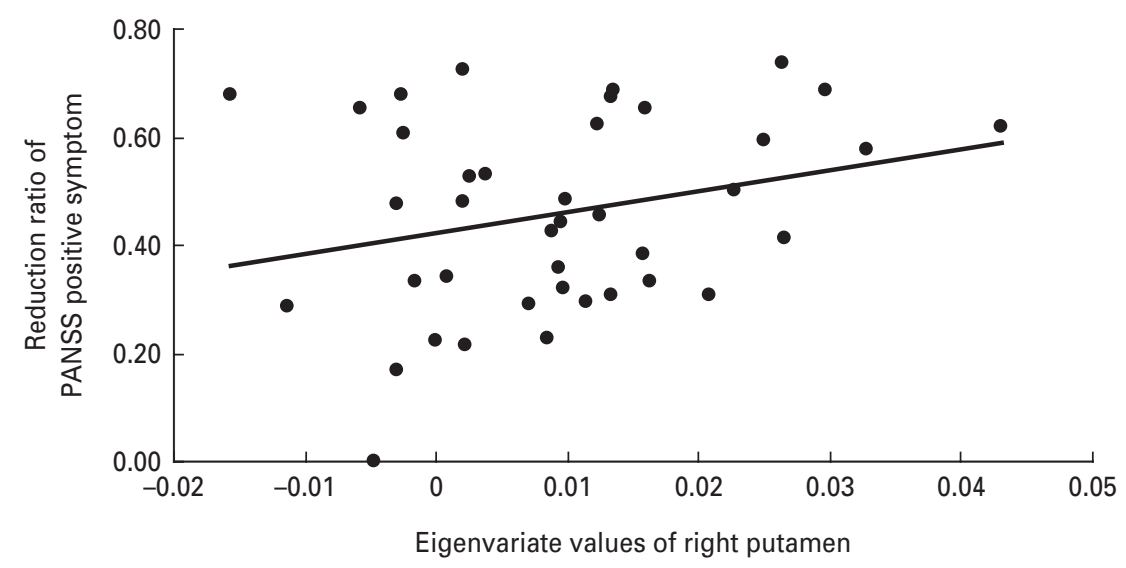

Fig. 2. The volume change in the right putamen was found to be positively correlated with the reduction ratio of positive symptoms $(r=0.350, p=0.034)$. PANSS, Positive and Negative Syndrome Scale.

mammalian brain proliferation by antagonizing dopamine at D-2 receptors on NSCs contributing to new neurons and glia in the adult rat brain (Kippin et al. 2005; Keilhoff et al. 2010). The antipsychotic olanzapine has also been found to significantly increase both the total number and density of newly generated neurons in the prefrontal cortex and dorsal striatum in rats (Wang et al. 2004). Beckmann \& Lauer (1997) reported that increased striatal volume is accompanied by an increased number of striatal neurons in patients with schizophrenia. Konradi \& Heckers (2001) also concluded that antipsychotic drugs might induce neuroplasticity. They suggested that the classic antipsychotic haloperidol has a significant effect on synapse formation and rearrangement, which may be important for its antipsychotic properties (Konradi \& Heckers, 2001). These studies prompt the speculation that the increased volume of putamen after 6 weeks antipsychotic treatment observed here might reflect neurogenesis and neuroplasticity.

In line with previous studies, which showed that the increased volume in striatum is associated with a reduction in positive symptoms (Taylor et al. 2005) and that increased caudate volume is related to the symptom improvement after olanzapine treatment (Okugawa et al. 2007), we found that increased putaminal volume was only positively related to the ratio of reduction in a positive symptom score in the current study. This is not consistent with some previous studies, which showed larger increases in caudate volume or putaminal volume associated with a higher dose of antipsychotic medication (Chakos et al. 1994; Gur et al. 1998; Beng-Choon et al. 2011) as we did not observe a relationship between the putaminal volume changes and the total antipsychotic dosages. This finding suggests that, to some extent, the increased volume in putamen might be a candidate biomarker to evaluate the efficiency of antipsychotic response in terms of improvement of positive symptoms of patients. In other words, the results might reflect an individual response to antipsychotic rather than a more general fixed dose-response. In previous studies, conventional and atypical antipsychotic have been considered to act differently on brain morphology. Volumetric changes in basal ganglia were thought to be much more likely with the use of conventional rather than atypical antipsychotics (Navari \& Dazzan, 2009). Conventional antipsychotics seemed to affect the basal ganglia (enlargement of the putamen) and cortical areas more extensively, while atypical antipsychotics were particularly associated with enlargement of the thalami (Dazzan et al. 2005). In the present study, when we removed four subjects who received conventional antipsychotics, the result was largely unchanged. This common effect of typical and atypical medication on basal ganglia volume is similar to that reported by Massana et al. (2005) after 3-months resperidione treatment and a significantly increased volume in the putamen was detected after 12 weeks of exposure to risperidone by Glenthoj et al. (2007). These studies agree that both conventional and atypical antipsychotic have effects on the basal ganglia in the early stage of treatment of schizophrenia. The trend towards a significant positive correlation between the increased volume of putamen and the improvement of positive symptoms still existed after excluding four patients who received conventional antipsychotic $(p=0.057, r=0.334)$, although the smaller sample size reduced the power to detect the significant correlation.

There are some limitations in this study. First, we included 66 patients at baseline; however, only 42 patients rescanned in 6 weeks and 40 patients' images qualified for analysis. The ratio of follow-up is thus $63.64 \%$, which may result in selective bias due to the willingness of the patients and/or other reasons 
(e.g. lack of response to the treatment, living in remote areas of the country, etc.). But there is no significant difference in duration of illness or clinical severity in 42 re-scanned patients and 24 unable to re-scan patients groups in baseline (duration of illness: $p=$ 0.9238; GAF: $p=0.2929$; PANSS total score: $p=0.5835$; PANSS positive symptoms: $p=0.1364$; PANSS negative symptoms : $p=0.1345$; PANSS general symptoms: $p=0.3636)$. Unfortunately, we did not have the treatment history for the subgroup who had not re-scanned due to various reasons (e.g. lost contact after patients were discharged from the hospital or unwilling to be rescanned after treatment, etc.). Second, this is a naturalistic study regarding the choice of treatment, so we did not control the type of antipsychotics that the patients received. Only four patients took conventional antipsychotics, so it was not possible to compare the effects of different antipsychotics on brain structure.

In present-day clinical practice, we are able to observe if a patient is responding after 6 weeks treatment by using clinical assessment (e.g. the reduction rate of positive and negative symptom score). However, those assessments used in present clinical practice are rather subjective and unstable and it is difficult to quantify the degree of treatment response without identifying objective biomarkers. Thus, it is becoming a 'hot' area that biomarkers would be better and promising indicators for assessment of treatment response. In this study, we did an explorative analysis and identified the increased volume change of putamen after 6 weeks antipsychotic treatment by using the MRI scan. In addition, the increased volume was related to the improvement of positive symptoms in patients with schizophrenia, which provided supportive evidence for future use in clinical practice. However, more independent studies are required to confirm this finding. Furthermore, it is worthwhile to seek biomarkers, which may predict treatment response at an even earlier stage, e.g. 2 weeks after treatment, and to identify biomarkers, which may eventually lead to personalized medication in the treatment of schizophrenia.

\section{Acknowledgements}

This work was partly funded by National Nature Science Foundation of China (30530300 and 30125014, T.L.; 30971056, W.Q.); the National Basic Research Program of China (973 Program 2007CB512301, T.L.; 2007CB512305, Q.G.); the National High Technology Research and Development Program of China (863 Program) (Grant No. 2009AA022702); NARSAD independent Investigator Award (T.L.); the Wellcome Trust (International Collaborative award to T.L.,
D.A.C. and X.L.) ; the China Postdoctoral Science Foundation (Grant No. 20090461337201003699 ).

\section{Declaration of Interest}

None.

\section{References}

Abi-Dargham A (2004). Do we still believe in the dopamine hypothesis? New data bring new evidence. International Journal of Neuropsychopharmacology 7, S1-S5.

Agid O, Kapur S, Arenovich T, Zipursky RB (2003). Delayed-onset hypothesis of antipsychotic action - a hypothesis tested and rejected. Archives of General Psychiatry 60, 1228-1235.

Annett M (1970). A classification of hand preference by association analysis. British Journal of Psychiatry 61, 303-321.

Ashburner J, Friston KJ (2004). Morphometry. In Human Brain Function (ed. R. S. J. Frackowiak). Academic Press, Elsevier Science: California, USA.

Atkins M, Burgess A, Bottomley C, Riccio M (1997). Chlorpromazine equivalents: a consensus of opinion for both clinical and research applications. Psychiatric Bulletin 21, 224-226.

Backman L, Ginovart N, Dixon RA, Wahlin TBR, Wahlin A, Halldin C, Farde L (2000). Age-related cognitive deficits mediated by changes in the striatal dopamine system. American Journal of Psychiatry 157, 635-637.

Beckmann H, Lauer M (1997). The human striatum in schizophrenia. II. Increased number of striatal neurons in schizophrenics. Psychiatry Research Neuroimaging 68, 99-109.

Beng-Choon H, Andreasen NC, Ziebell S, Pierson R, Magnotta V (2011). Long-term antipsychotic treatment and brain volumes: a longitudinal study of first-episode schizophrenia. Archives of General Psychiatry 68, 128-137.

Boonstra G, van Haren N, Schnack HG, Cahn W, Burger H, Boersma M, de Kroon B, Grobbee DE, Hulshoff Pol HE, Kahn RS (2011). Brain volume changes after withdrawal of atypical antipsychotics in patients with first-episode schizophrenia. Journal of Clinical Psychopharmacology 31, 146-153.

Borta A, Hoglinger GU (2007). Dopamine and adult neurogenesis. Journal of Neurochemistry 100, 587-595.

Chakos MH, Lieberman JA, Bilder RM, Borenstein M, Lerner G, Bogerts B, Wu HW, Kinon B, Ashtari M (1994). Increase in caudate nuclei volumes of first-episode schizophrenia-patients taking antipsychotic-drugs. American Journal of Psychiatry 151, 1430-1436.

Chua SE, Cheung C, Cheung V, Tsang JTK, Chen EYH, Wong JCH, Cheung JPY, Yip L, Tai KS, Suckling J, McAlonan GM (2007). Cerebral grey, white matter and csf in never-medicated, first-episode schizophrenia. Schizophrenia Research 89, 12-21.

Chua SE, Deng Y, Chen EYH, Law CW, Chiu CPY, Cheung C, McAlonan GM (2009). Early striatal 
hypertrophy in first-episode psychosis within 3 weeks of initiating antipsychotic drug treatment. Psychological Medicine 39, 793-800.

Dazzan P, Morgan KD, Orr K, Hutchinson G, Chitnis X, Suckling J, Fearon P, McGuire PK, Mallett RM, Jones PB, Leff J, Murray RM (2005). Different effects of typical and atypical antipsychotics on grey matter in first episode psychosis: the AESOP study. Neuropsychopharmacology 30, 765-774.

Deng MY, McAlonan GM, Cheung C, Chiu CPY, Law CW Cheung V, Sham PC, Chen EYH, Chua SE (2009). A naturalistic study of grey matter volume increase after early treatment in anti-psychotic naive, newly diagnosed schizophrenia. Psychopharmacology 206, 437-446.

Emsley R, Rabinowitz J, Medori R (2006). Time course for antipsychotic treatment response in first-episode schizophrenia. American Journal of Psychiatry 163, 743-745.

Falkai P, Wobrock T, Lieberman J, Glenthoj B, Gattaz WF, Moller HJ (2005). World Federation of Societies of Biological Psychiatry (WFSBP) - guidelines for biological treatment of schizophrenia. Part 1: Acute treatment of schizophrenia. World Journal of Biological Psychiatry 6, 132-191.

First MB, Spitzer RL, Gibbon M, Williams JB (1996). Structured Clinical Interview for DSM-IV Axis I Disorders-Non-Patient Edition (SCID-I/NP), version 2.0. New York State Psychiatric Institute, Biometrics Research: New York.

Glenthoj A, Glenthoj BY, Mackeprang T, Pagsberg AK, Hemmingsen RP, Jernigan TL, Baare WFC (2007). Basal ganglia volumes in drug-naive first-episode schizophrenia patients before and after short-term treatment with either a typical or an atypical antipsychotic drug. Psychiatry Research: Neuroimaging 154, 199-208.

Gunduz H, Wu HW, Ashtari M, Bogerts B, Crandall D, Robinson DG, Alvir J, Lieberman J, Kane J, Bilder R (2002). Basal ganglia volumes in first-episode schizophrenia and healthy comparison subjects. Biological Psychiatry 51, 801-808.

Gur RE, Maany V, Mozley D, Swanson C, Bilker W, Gur RC (1998). Subcortical MRI volumes in neuroleptic-naive and treated patients with schizophrenia. American Journal of Psychiatry 155, 1711-1717.

Harris MSH, Reilly JL, Keshavan MS, Sweeney JA (2006). Longitudinal studies of antisaccades in antipsychotic-naive first-episode schizophrenia. Psychological Medicine 36, 485-494.

Heinz A, Schlagenhauf F (2010). Dopaminergic dysfunction in schizophrenia: salience attribution revisited. Schizophrenia Bulletin 36, 472-485.

Honea R, Crow TJ, Passingham D, Mackay CE (2005). Regional deficits in brain volume in schizophrenia: a meta-analysis of voxel-based morphometry studies. American Journal of Psychiatry 162, 2233-2245.

Howes OD, Kapur S (2009). The dopamine hypothesis of schizophrenia: version III-025EF. The final common pathway. Schizophrenia Bulletin 35, 549-562.

Huang XQ, Lui S, Deng W, Chan RCK, Wu QZ, Jiang LJ, Zhang JR, Jia ZY, Li F, Li XL, Chen L, Li T, Gong QY (2009). Localization of cerebral functional deficits in treatment-naive, first-episode schizophrenia using restingstate fMRI. NeuroImage 49, 2901-2906.

Ifthikharuddin SF, Shrier DA, Numaguchi Y, Tang X, Ning R, Shibata DK, Kurlan R (2000). MR volumetric analysis of the human basal ganglia: normative data. Academic Radiology 7, 627-634.

Jayakumar PN, Venkatasubramanian G, Gangadhar BN, Janakiramaiah N, Keshavan MS (2005). Optimized voxel-based morphometry of gray matter volume in first-episode, antipsychotic-naive schizophrenia. Progress in Neuro-Psychopharmacology \& Biological Psychiatry 29, 587-591.

Jentsch JD, Roth RH (1999). The neuropsychopharmacology of phencyclidine: from NMDA receptor hypofunction to the dopamine hypothesis of schizophrenia.

Neuropsychopharmacology 20, 201-225.

Kawasaki Y, Suzuki M, Takahashi T, Nohara S, McGuire PK, Seto H, Kurachi M (2008). Anomalous cerebral asymmetry in patients with schizophrenia demonstrated by voxel-based morphometry. Biological Psychiatry 63, 793-800.

Kay SR, Fiszbein A, Opler LA (1987). The Positive and Negative Syndrome Scale (PANSS) for schizophrenia. Schizophrenia Bulletin 13, 261-276.

Keilhoff G, Grecksch G, Bernstein HG, Roskoden T, Becker A (2010). Risperidone and haloperidol promote survival of stem cells in the rat hippocampus. European Archives of Psychiatry \& Clinical Neuroscience 260, 151-162.

Kippin TE, Kapur S, van der Kooy D (2005). Dopamine specifically inhibits forebrain neural stem cell proliferation, suggesting a novel effect of antipsychotic drugs. Journal of Neuroscience 25, 5815-5823.

Konradi C, Heckers S (2001). Antipsychotic drugs and neuroplasticity: insights into the treatment and neurobiology of schizophrenia. Biological Psychiatry 50, 729-742.

Lahti AC, Weiler MA, Holcomb HH, Tamminga CA, Cropsey KL (2009). Modulation of limbic circuitry predicts treatment response to antipsychotic medication: a functional imaging study in schizophrenia. Neuropsychopharmacology 34, 2675-2690.

Lang DJ, Kopala LC, Vandorpe RA, Rui Q, Smith GN, Goghari VM, Honer WG (2001). An MRI study of basal ganglia volumes in first-episode schizophrenia patients treated with risperidone. American Journal of Psychiatry 158, 625-631

Larisch R, Meyer W, Klimke A, Kehren F, Vosberg H, Muller-Gartner HW (1998). Left-right asymmetry of striatal dopamine D2 receptors. Nuclear Medicine Communication 19, 781-787.

Lehman AF, Lieberman JA, Dixon LB, McGlashan TH, Miller AL, Perkins DO, Kreyenbuhl J, McIntyre JS, Charles SC, Altshuler K, Cook I, Cross CD, Mellman L, Moench LA, Norquist G, Twemlow SW, Woods S, Yager J, Gray SH, Askland K, Pandya R, Prasad K, Johnston R, Nininger J, Peele R, Anzia DJ, Benson RS, Lurie L, Walker RD, Kunkle R, Simpson A, Fochtmann LJ, Hart C, Regier D (2004). Practice guideline for the treatment of patients with schizophrenia, second edition. American Journal of Psychiatry 161, 1-56. 
Leow AD, Klunder AD, Jack CR, Toga AW, Dale AM, Bernstein MA, Britson PJ, Gunter JL, Ward CP, Whitwell JL, Borowski BJ, Fleisher AS, Fox NC, Harvey D, Kornak J, Schuff N, Studholme C, Alexander GE, Weiner MW, Thompson PM (2006). Longitudinal stability of MRI for mapping brain change using tensor-based morphometry. NeuroImage 31, 627-640.

Leucht S., Busch R, Hamann J, Kissling W, Kane JM (2005). Early-onset hypothesis of antipsychotic drug action: a hypothesis tested, confirmed and extended. Biological Psychiatry 57, 1543-1549.

Lui S, Deng W, Huang XQ, Jiang LJ, Ma XH, Chen HF, Zhang TJ, Li XL, Li DM, Zou L, Tang HH, Zhou XHJ, Mechelli A, Collier DA, Sweeney JA, Li T, Gong QY (2009). Association of cerebral deficits with clinical symptoms in antipsychotic-naive first-episode schizophrenia: an optimized voxel-based morphometry and resting state functional connectivity study. American Journal of Psychiatry 166, 196-205.

Massana G, Salgado-Pineda P, Junque C, Perez M, Baeza I, Pons A, Massana J, Navarro V, Blanch J, Morer A, Mercader JM, Bernardo M (2005). Volume changes in gray matter in first-episode neuroleptic-naive schizophrenic patients treated with risperidone. Journal of Clinical Psychopharmacology 25, 111-117.

Morosini PL, Magliano L, Brambilla L, Ugolini S, Pioli R (2000). Development, reliability and acceptability of a new version of the DSM-IV Social and Occupational Functioning Assessment Scale (SOFAS) to assess routine social functioning. Acta Psychiatrica Scandinavica 101, 323-329.

Navari S, Dazzan P (2009). Do antipsychotic drugs affect brain structure? A systematic and critical review of MRI findings. Psychological Medicine 39, 1763-1777.

Okugawa G, Nobuhara K, Takase K, Saito Y, Yoshimura M, Kinoshita T (2007). Olanzapine increases grey and white matter volumes in the caudate nucleus of patients with schizophrenia. Neuropsychobiology 55, 43-46.

Premkumar P, Kumari V, Corr PJJ, Sharma T (2006). Frontal lobe volumes in schizophrenia: effects of stage and duration of illness. Journal of Psychiatric Research 40, 627-637.

Reeves SJ, Grasby PM, Howard RJ, Bantick RA, Asselin MC, Mehta MA (2005). A positron emission tomography (PET) investigation of the role of striatal dopamine (D2) receptor availability in spatial cognition. NeuroImage 28, 216-226.

Schultz W (2007). Behavioral dopamine signals. Trends in Neurosciences 30, 203-210.

Seeman P, Kapur S (2000). Schizophrenia: more dopamine, more D2 receptors. Proceedings of the National Academy of Sciences USA 97, 7673-7675.

Shenton ME, Dickey CC, Frumin M, McCarley RW (2001). A review of MRI findings in schizophrenia. Schizophrenia Research 49, 1-52.

Shihabuddin L, Buchsbaum MS, Hazlett EA, Haznedar MM, Harvey PD, Newman A, Schnur DB, Spiegel-Cohen
J, Wei TS, Machac J, Knesaurek K, Vallabhajosula S, Biren MA, Ciaravolo TM, Luu-Hsia C (1998). Dorsal striatal size, shape, and metabolic rate in never-medicated and previously medicated schizophrenics performing a verbal learning task. Archives of General Psychiatry 55, 235-243.

Smieskova R, Fusar-Poli P, Allen P, Bendfeldt K, Stieglitz RD, Drewe J, Radue EW, McGuire PK, Riecher-Rossler A, Borgwardt SJ (2009). The effects of antipsychotics on the brain: what have we learnt from structural imaging of schizophrenia? - A systematic review. Current Pharmaceutical Design 15, 2535-2549.

Steen RG, Mull C, McClure R, Hamer RM, Lieberman JA (2006). Brain volume in first-episode schizophrenia systematic review and meta-analysis of magnetic resonance imaging studies. British Journal of Psychiatry 188, 510-518.

Takao H, Abe O, Yamasue H, Aoki S, Kasai K, Ohtomo K (2010). Cerebral asymmetry in patients with schizophrenia: a voxel-based morphometry (VBM) and diffusion tensor imaging (DTI) study. Journal of Magnetic Resonance Imagine 31, 221-226.

Taylor S, Christensen JD, Holcomb JM, Garver DL (2005). Volume increases in striatum associated with positive symptom reduction in schizophrenia: a preliminary observation. Psychiatry Research Neuroimaging 140, 85-89.

Toda M, Abi-Dargham A (2007). Dopamine hypothesis of schizophrenia: making sense of it all. Current Psychiatry Reports 9, 329-336.

Tomelleri L, Jogia J, Perlini C, Bellani M, Ferro A, Rambaldelli G, Tansella M, Frangou S, Brambilla P (2009). Brain structural changes associated with chronicity and antipsychotic treatment in schizophrenia. European Neuropsychopharmacology 19, 835-840.

Volkow ND, Gur RC, Wang GJ, Fowler JS, Moberg PJ, Ding YS, Hitzemann R, Smith G, Logan J (1998). Association between decline in brain dopamine activity with age and cognitive and motor impairment in healthy individuals. American Journal of Psychiatry 155, 344-349.

Wang HD, Dunnavant FD, Jarman T, Deutch AY (2004). Effects of antipsychotic drugs on neurogenesis in the forebrain of the adult rat. Neuropsychopharmacology 29, 1230-1238.

Watkins KE, Paus T, Lerch JP, Zijdenbos A, Collins DL, Neelin P, Taylor J, Worsley KJ, Evans AC (2001). Structural asymmetries in the human brain: a voxel-based statistical analysis of 142 MRI scans. Cerebral Cortex 11, 868-877.

Woods SW (2003). Chlorpromazine equivalent doses for the newer atypical antipsychotics. Journal of Clinical Psychiatry 64, 663-667.

Yamashita K, Yoshiura T, Hiwatashi A, Noguchi T, Togao O, Takayama Y, Nagao E, Kamano H, Hatakenaka M, Honda H (2011). Volumetric asymmetry and differential aging effect of the human caudate nucleus in normal individuals: a prospective MR imaging study. Journal of Neuroimaging 21, 34-37. 